\title{
The Stable Bounded Theory. An Alternative to Project the Net Migration. The Case of Mexico
}

\author{
By Javier González-Rosas* \\ Iliana Zárate-Gutiérrez ${ }^{\dagger}$
}

\begin{abstract}
The Interior Ministry of Mexico in 2011 and the Pew Hispanic Center of the United States in 2012, reported that the outflow of the Mexicans in the 2005-2010 period, was compensated with return of countrymen from the United States and immigrants. That is, there was no Mexican net migration. In this context, the paper has three objectives, first, to prove that net migration tends to stabilize, second, to estimate the value at which stability will occur, and third, to do stochastic forecasts for the 2011-2020 period. The Methodology used was to apply the Stable Bounded Theory, to the data of the 2004-2010 period calculated by national expert demographers and the Mexican Society of Demography. Using the Stable Bounded Theory we prove that net migration of Mexico will stabilize and we also calculate the stability value. The major results indicate that net migration nowadays is not zero, but tends to stabilize at this value. Also, they show that population loss will continue decreasing at a rate of 36.12 habitants, which implies that in 2016 2,007 persons are going to leave the country, in 2018819 people will leave the country and finally in 2020 the number of people leaving the country will decrease to 334. Net migration each time decreases and reaches closer to the absolute zero.
\end{abstract}

Keywords: Forecasts, International migration, Net migration, Stability.

\section{Introduction}

In 2011, Lopez and Gasper and the Mexican Society of Demography (SOMEDE by its acronym in Spanish), using information from Mexican and American sources, carried out exercises to estimate international migration which were used as support for Mexico's census conciliation. Mexican sources used by Lopez and Gaspar were population censuses of 1990, 2000 and 2010, while Americans were a sample of the population census of 2000 and the American Community Survey (ACS) of the same year. Mexican sources used by SOMEDE were population censuses of 1970, 1980, 1990 and 2010, while Americans were the ACS of 2000-2009 (CONAPO, 20015, p. 15). Lopez and Gaspar estimated the net migration balance (SNM by its acronym in Spanish) for period 1990-2008 and SOMEDE for 1990-2010.

The data of these two exercises indicate that in the last years (1990-2010), SNM in Mexico had important changes. In period 1990-2004 both time series show that a trend of the SNM was going down. But the next year, the trend

\footnotetext{
* Director of Socio-Economic Studies and International Migration, National Population Council, México.

${ }^{\dagger}$ Assistant Director of State and Local Coordination, National Population Council, México.
} 
changed radically according to both time series and the SNM began to increase. Even Lopez and Gaspar estimated in 2008 a positive SNM of little more than 17,000 persons. That is, in this year for the first time in a long time the Mexican population increased due to international migration. SOMEDE by its part estimated in 2009 a SNM of 40,405 persons and for 2010 of 40,992. There was almost no change, something that it had not occurred in a long time. These results suggest the hypothesis that Mexico's SNM tends to stabilize at the value zero. The objective of this paper is to prove this hypothesis and besides to elaborate projections of Mexico's SNM for period 2011-2020.

\section{Literature Review}

A forecast of Mexico's population has traditionally been carried out using the demographic components method, which is based on the estimation of births, deaths, and net migrants, which are the elements that determine the change in human populations. This method, estimates births and deaths, projecting fertility and mortality rates through logistic functions. Also deterministic and probabilistic approaches have been used. However, net migration has not been projected using mathematical models and its forecast has been done only setting assumptions about their behavior in future. In this paper Mexico's net migration is forecasted for the first time using a mathematical model and stochastic approach.

Since the 1990s, there has been an increasing need to move away from deterministic projections to probabilistic projections. Probabilistic projections have the advantage in that they specify the likelihood that a particular future population value will occur. In deterministic projections, we do not have particular likelihood, but we only have a value which most likely is going to occur (Raymer et al. 2012).

Also it is very important to consider if population forecasts are going to be used to formulate policies regarding the labour market, health care, economic development or pension systems because then the uncertainty involved should be quantified and included in those forecasts (Alders et al. 2007).

The classical theory of population with age structure assumes that agespecific birth and death rates are constant in time or change deterministically. With this idea in mind various models have been developed for age-structured populations with age specific vital rates that vary stochastically, i.e. with a random component (Cohen 1985: 106).

About net migration, the urban topic on migration forecasts is very important. Montgomery and Hewett estimated in 2001 that $36 \%$ of recent urban migrants of sixty-nine countries have moved directly from rural areas and $64 \%$ have moved from cities, suggesting a very different process of migration that is necessary to have in mind in forecast exercises. This data does not change the conclusion that most future population growth will occur in urban areas, but it does suggest that urban growth may be more spread out than previously thought and may follow a more complex process (Lloyd 2017). 
Age-sex-specific population forecasts are derived through stochastic population renewal using forecasts of mortality, fertility and net migration. Functional data models with time series coefficients are used to model age-specific mortality and fertility rates. Due to, the fact that generally detailed migration data is lacking, net migration by age and sex is estimated as the difference between historic annual population data and successive populations one year ahead derived from a projection using fertility and mortality data. Using a Monte Carlo simulation of future fertility, mortality and net migration, which can be combined using the cohort-component method it is possible to obtain age-specific forecasts of the population by sex. The distribution of the forecasts provides probabilistic prediction intervals (Hyndman and Booth 2008).

\section{Methodology}

\section{The Equation of Net Migration and Time}

Figure 1 shows the estimates of Lopez and Gaspar and SOMEDE. As can be seen, the estimated volumes are very different. However, in general they show very similar behavior. From 1990 to 2004 both series show a decreasing trend, but from 2004 the trend has changed to the upside. In order to have a single time series, the data used in this article was the average of both series (see Table 1).

If we suppose that at each year the mean of net migration is given by the curve of the Figure 2, then this would explain why the observations deviate up and down the curve, and therefore, the equation of the behavior must have a predictable component, and another unpredictable one. The predictable part is known as the deterministic component, and is given by the curve of a mathematical function which depends on time, while the unpredictable part is known as the random component and is determined by a random variable that depends of a mean and a variance (Medhi 1981: 223).

Figure 1. Net Migration According Source, 1990-2010

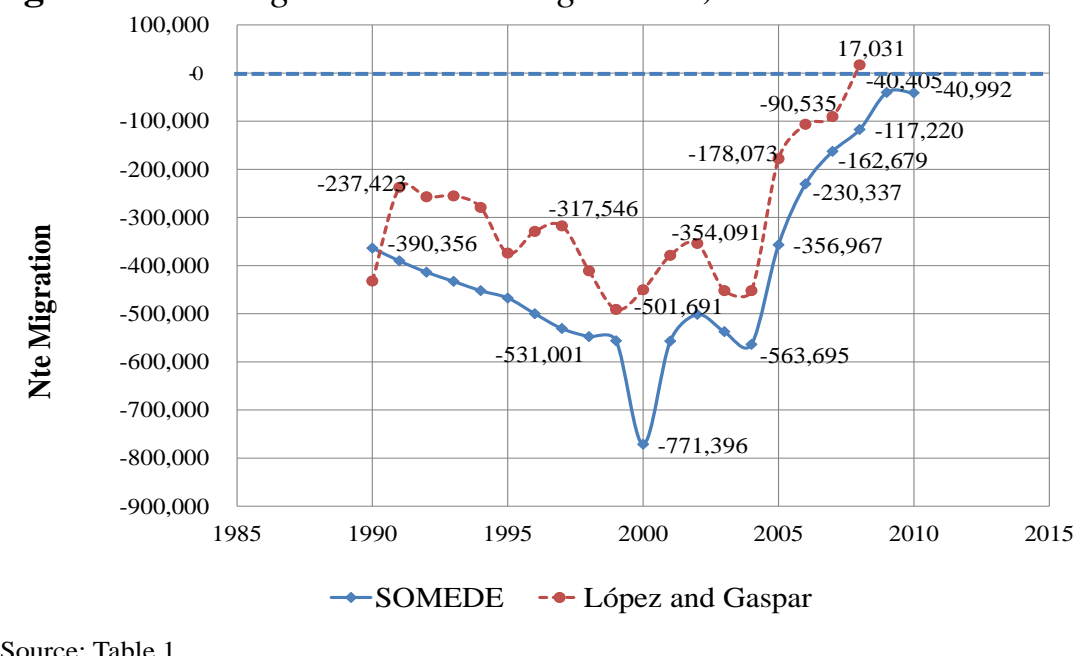

Source: Table 1 
Table 1. Net Migration in Mexico According to Source and Average, 2004-2010

\begin{tabular}{|c|c|c|c|}
\hline Year & $\begin{array}{c}\text { SOMEDE } \\
\text { Mexican Society } \\
\text { of Demography }\end{array}$ & $\begin{array}{c}\text { Lopez and } \\
\text { Gaspar }\end{array}$ & Average \\
\hline 2004 & $-563,695$ & $-452,093$ & $-507,894$ \\
\hline 2005 & $-356,967$ & $-178,073$ & $-267,520$ \\
\hline 2006 & $-230,337$ & $-106,495$ & $-168,416$ \\
\hline 2007 & $-162,679$ & $-90,535$ & $-126,607$ \\
\hline 2008 & $-117,220$ & -17.031 & $-50,094.5$ \\
\hline 2009 & $-40,405$ & & $-40,405$ \\
\hline 2010 & $-40,992$ & & $-40,992$ \\
\hline
\end{tabular}

Source: CONAPO (2015).

Therefore, to explain the net migration evolution through time, a theory which combines these two components is needed. If it is supposed that net migration will tend to stabilize then the candidate theory, would be the Stable Bounded Theory (Gonzalez-Rosas 2012).

The Stable Bounded Theory basing in the data of net migration trend of the Figure 2, and under the hypothesis that exists a value $K$ where net migration will stabilize, proves that an equation which adequately describes the evolution of net migration through time is:

$$
S_{t}=K-\gamma e^{r t}+\varepsilon_{t} \quad ; \quad r<0
$$

Where:

$S_{t}$ denotes the random variable of net migration at time $t$

$t$ is time variable,

$K,-\gamma$ and $\mathrm{r}$ are unknown parameters, and

The $\varepsilon_{f}$ are random variables such that we can suppose as independent ones, distributed Normal with a mean of $\mu_{\varepsilon}=0$ and a constant variance of $\sigma_{\varepsilon}^{2}$ also unknown.

Figure 2. Average Net Migration in Mexico, 2004-2010

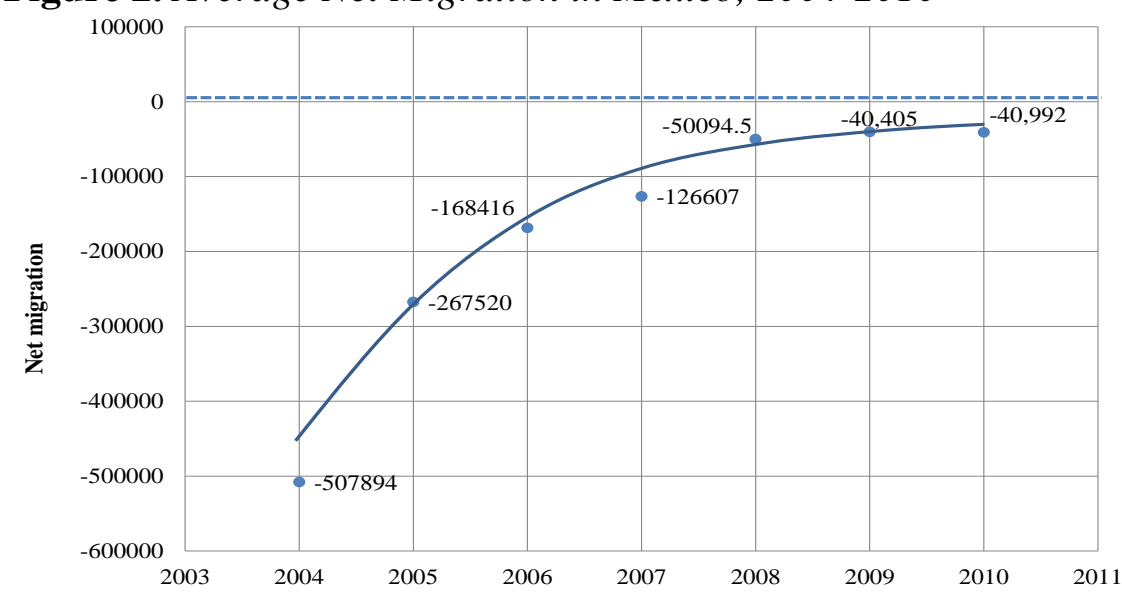

Source: Table 1 
As you can realize, the equation (1) has four unknown parameters $K,-\gamma, r$ and $\sigma_{\varepsilon}^{2}$, also establishes four assumptions for $S_{t}$, independence, normality, zero mean, and constant variance. It is absolutely necessary that $\varepsilon_{t}$ complies with these assumptions in order to get the best estimators of parameters, and therefore more accurate and reliable forecasts, so that, it is essential to prove they are fulfilled.

The parameter $K$ is the stability value and is also known as the bound of net migration, because its mean will always be lesser than $K$ for all values of time (Leithold 1973: 663, Lehman 2000: 41). The letters $-\gamma$ and $r$ represent the quickness parameters, because they determine the speed of the approach of the deterministic part to the stability.

If you analyze the equation (1), you will observe an increasing function, and if you observe Figure 2, you will also note that net migration is increased through time. On the other hand, as $r$ is negative, then when time $t$ tends to infinity, $S_{t}$ will approach to $K$, but always will be less, therefore, $K$ is an upper bound, and hence represents the stability value of net migration. Namely, the equation (1) describes the observed behavior of net migration at present and the behavior of stability in the future. However, only we can calculate the forecasts, if we estimate the parameters $K,-\gamma$ and $r$.

\section{Estimation of Parameters}

According to Draper and Smith (1966) the deterministic part of the equation (1) is nonlinear in the parameters $K,-\gamma$ and $r$, so that, they cannot be estimated by the least squares method. Nevertheless, when in the deterministic part, $K$ is moved on the left of equality, it is multiplied by -1 , and if finally a natural logarithm is applied, we have that,

$$
\operatorname{Ln}\left(K-S_{t}\right)=\operatorname{Ln} \gamma+r t
$$

That is to say, the result is a linear equation in the parameters $\operatorname{Ln} \gamma$ and r, and therefore, they can be estimated by the ordinary least squares method or by a generalized least squares method. This means that, the parameters of the deterministic part of (1) can be estimated in two steps. The Stable Bounded Theory proves that there exists a procedure which estimates $K$ at first, and after, using the estimation of $K$, estimates the parameters $-\gamma$ and $r$. The theory proves besides that the estimators of the second step keep two of three optimal properties of the estimators. The variable $\operatorname{Ln}\left(K-S_{t}\right)$ is known as the transformed of the net migration (Gonzalez-Rosas 2010: 65).

\section{Estimation of $K$}

According to the Stable Bounded Theory, we draw straight lines to join the successive points of net migration. In Figure 3 you can observe that when the points are approaching zero, the straight line we drew is inclined more and 
more, such that, the straight line of the points which are more near to zero is almost parallel to the axis time. The Stable Bounded Theory affirms this behavior is empirical evidence of the mean of net migration and tends to stabilize in the zero value.

Because the slope of a straight line between two points measures its inclination, and as the slope of a straight line that is parallel to axis time is zero (Leithold 1973: 138), then, if the zero is the stability value of net migration, when the points are approaching to zero, the slope value must also tend to approach zero. In order to determine the stability value, we calculate the slopes and the average values between $y_{i}$ and $y_{i+1}$ of net migration, as follows,

$$
\begin{gathered}
\Delta_{i}=\frac{y_{i+1}-y_{i}}{t_{i+1}-t_{i}} \\
V M_{i}=y_{i}+\frac{y_{i+1}-y_{i}}{2}
\end{gathered}
$$

Where:

$\Delta_{i}$ denotes the slope between the points $\left(\mathrm{t}, y_{i}\right)$ and $\left(\mathrm{t}+1, y_{i+1}\right)$ of the twodimensional space defined by net migration and time (Leithold 1973: 137), and $V M_{i}$ denotes the average value between $y_{i}$ and $y_{i+1}$ (see Table 2)

Table 2. Time, Net Migration, Average Value and Slope in Mexico, 2004-2010

\begin{tabular}{|l|c|c|c|c|}
\hline Year & Time & $\begin{array}{c}\text { Net } \\
\text { Migration }\end{array}$ & $\begin{array}{c}\text { Average } \\
\text { Value }\left(V M_{i}\right)\end{array}$ & $\begin{array}{c}\text { Slope } \\
\left(\Delta_{i}\right)\end{array}$ \\
\hline 2004 & 0 & $-507,894$ & $-387,707$ & 240,374 \\
\hline 2005 & 1 & $-267,520$ & $-217,968$ & 99,104 \\
\hline 2006 & 2 & $-168,416$ & $-147,511.5$ & 41,809 \\
\hline 2007 & 3 & $-126,607$ & $-88,350.8$ & $76,512.5$ \\
\hline 2008 & 4 & $-50,094.5$ & $-45,209.8$ & $9,689.5$ \\
\hline 2009 & 5 & $-40,405$ & $-40,698.5$ & -587 \\
\hline 2010 & 6 & $-40,992$ & & \\
\hline
\end{tabular}

Source: Table 1, own calculations based in equations 3 and 4 .

In the Figure 4, we drew in the $\mathrm{X}$ axis the average values (VM), and in the $\mathrm{Y}$ axis, the slopes values. You can observe that the behavior of slope through net migration is also random, however, in this case, the mean of the slope is given by a straight line and the deviation of the observations by a new random variable, namely, also behavior has two components, one is deterministic and another is random. You can also observe, that the inclination of the straight line of Figure 4 indicates that when net migration approaches to zero, the mean of the slope also approaches to zero. The mathematical relationship between the slope and net migration is given by the next equation:

$$
\Delta_{i}=\alpha+\beta S_{i}+\theta_{i}
$$


Where:

$\Delta_{i}$ denotes the $\mathrm{i}$ value of the slope,

$\alpha$ and $\beta$ are unknown constants, and

The $\theta_{i}$ are random variables which we supposed independents with Normal distribution and whose mean $\mu_{\theta}=0$, and constant variance $\sigma_{\theta}^{2}$.

Figure 4. Slopes According the Net Migration in México, 2004-2010

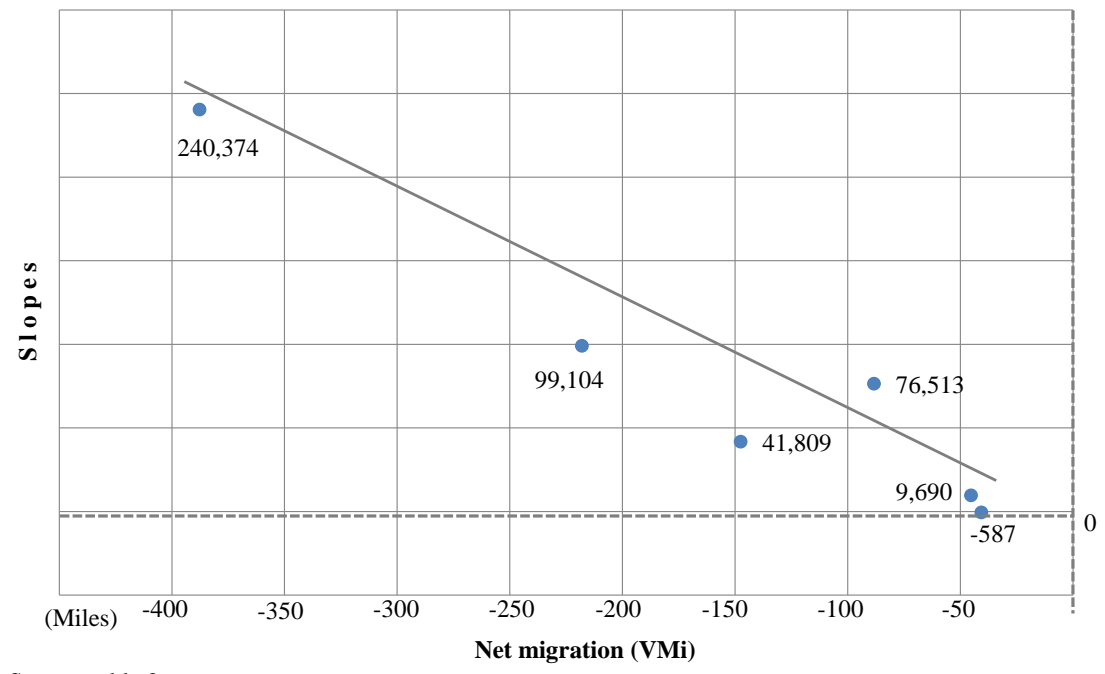

Source: table 2

Since a geometric point of view, the stability value of net migration is the number where the straight line of the Figure 4 crosses the $X$ axis. In the figure you can observe that the straight line seems to cross in the zero value. From a mathematical point of view, the Stable Bounded Theory proves that the numerical value of stability $K$ is the value of net migration in which the equation (5) is zero, therefore to calculate $K$, first, the deterministic part of (5) is zero,

$$
0=\alpha+\beta S_{i}
$$

And after it is solved for $S_{i}$

$$
S_{i}=\frac{-\alpha}{\beta}
$$

Therefore $K=-\alpha / \beta$, such that, when we estimate the parameters $\alpha$ and $\beta$ of the equation (5), we have that the formula (6) is an estimator of the stability value. The Stable Bounded Theory proves that if $\alpha$ and $\beta$ are estimated by ordinary least squares or by generalized least squares then $K$ is an unbiased and consistent estimator. 
Table 3. The Data to Prove Statistical Significance of the Parameters of Model (3)

\begin{tabular}{|c|c|c|c|c|}
\hline Variable & Coefficient & $\begin{array}{c}\text { Standard } \\
\text { Error }\end{array}$ & $\mathbf{t}$ & $\mathbf{P}>/ \mathbf{t} / \mathbf{1}$ \\
\hline$S_{i}$ & -0.6379 & 0.096426 & -6.62 & 0.003 \\
\hline Constant & $-20,797.77$ & $18,924.09$ & -1.1 & 0.333 \\
\hline
\end{tabular}

To calculate the stability value of net migration in Mexico, we adjust a linear regression simple model to the data of Figure 4 . In Table 3 you can observe the $p$-values of $\alpha$ and $\beta$ to prove their statistical significance. As you can see, $\beta(-0.6379)$ is statistically significant, but $\alpha(-20,797.77)$ is not, which means that $\alpha=0$. This proves mathematically what Figure 4 suggests, that is, the stability value of the mean of net migration in Mexico is zero, because,

$$
K=\frac{0}{-0.6379}=0
$$

It is very important to point out that $K$ is a bound for the mean of net migration, but is not it for the observations, which will be able to be positives, negatives or even zero, as, the observations occur randomly around the mean.

\section{Estimation of the Quickness Parameters}

According to the Stable Bounded Theory, model (1) describes adequately the evolution of net migration through time and is stabilized at the value $K$. Therefore, if in Mexico $K$ is zero, then equations (1) and (2) are simplified as follows,

$$
\begin{gathered}
S_{t}=-\gamma e^{r t}+\varepsilon_{t} \\
\operatorname{Ln}\left(-S_{t}\right)=\operatorname{Ln} \gamma+r t+\delta_{t}
\end{gathered}
$$

Where:

$S_{t}$ denotes the net migration in time $t$, $t$ denotes time variable,

$L n \gamma$ and $r$ are unknown constants, and

The $\delta_{t}$ are random variables that are supposed independents with the Normal Distribution, mean $\mu_{\delta}=0$ and constant variance $\sigma_{\delta}^{2}$.

In Figure 5, you can observe that relationship between the transformed of net migration and time $t$ in Mexico, is given by a straight line, proving the result of the theory, and therefore is linear in the parameters $\operatorname{Ln} \gamma$ and $r$. In order to estimate them, we adjust a linear regression simple model to data of Figure 5. 
Figure 5. Transformed According Time in Mexico, 2004-2010

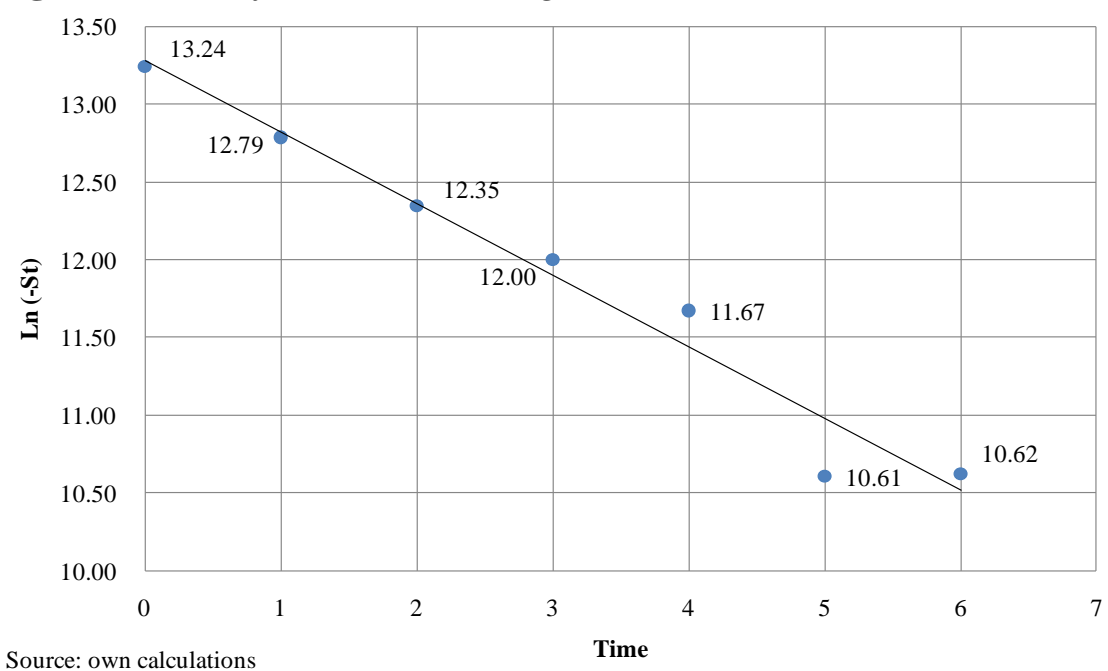

In Table 4 you can observe estimates of ordinaries minimum squares of the parameters and the $p$-values to prove their statistical significance. As you can see, both parameters are significant statistically with values $\operatorname{Ln} \gamma=12.983$ and $r=-0.4482$, so that, to obtain the estimation of $-\gamma$, first we applied the exponential function to $\operatorname{Ln} \gamma=12.983$, and after we multiply by -1 , obtaining finally $-\gamma=-434,955.93$.

Table 4. The Data to Prove the Statistical Significance of the Parameters of Model (4)

\begin{tabular}{|l|c|c|c|c|}
\hline Variable & Coefficient & $\begin{array}{c}\text { Standar } \\
\text { Error }\end{array}$ & $\mathbf{t}$ & $\mathbf{P}>/ \mathbf{t} /$ \\
\hline$t$ & -0.4482 & 0.0465 & -9.64 & 0.0000 \\
\hline Constant & 12.983 & $18,924.09$ & 77.48 & 0.0000 \\
\hline
\end{tabular}

Using the estimated parameters, we calculate the reduction annual rate (RAR) of the net migration as follows:

$$
\begin{gathered}
R A R=\frac{-\gamma e^{r t}+\gamma e^{r t}}{-\gamma e^{r t}} X 100 \\
R A R=\frac{-\gamma e^{r t}\left(1-e^{r t}\right)}{-\gamma e^{r t}} X 100 \\
R A R=\left(1-e^{r}\right) X 100 \\
R A R=\left(1-e^{-0.4482}\right) X 100 \\
R A R=36.12 \backslash \%
\end{gathered}
$$


This data means the reduction annual rate in Mexico is constant through time, and therefore the mean of the random variable of net migration will reduce each year by 36.2 percent

\section{Estimation of the Variance of Random Component}

When we estimated the bound and the quickness parameters, the deterministic component of the behavior equation of net migration through time, stayed completely specified. However, the estimation process has not finished, still the estimation of variance of the $\varepsilon_{t}$ random variables is missing. This estimation was obtained, at first, by generating $\varepsilon_{t}$ observations, and after by verifying assumptions. According to Montgomery and Peck (1982: 48) the observations are obtained with the residual amounts, which are defined as follows,

$$
\hat{\varepsilon}=S_{t}-\hat{S}_{t}
$$

Where:

$\hat{\varepsilon}_{t}$ denotes the residual at time $t$,

$S_{t}$ was referred to net migration observed at time $t$, and

$\hat{S}_{t}$ denotes net migration estimated at time.

In Table 5 we present the residuals. As you can observe, the estimation of the mean is $-7,151.7$, however, a hypothesis test with a 5 percent of significance level proved that the true mean is zero, which means, the $\varepsilon_{t}$ fulfill with assumption of zero mean.

The other three $\varepsilon_{t}$ fundamental assumptions which are normality, independence and constant variance also they were fulfilled. In these conditions, according to Box and Jenkins (1970) the major estimator of the variance of the random variable $\varepsilon_{t}$ is,

$$
{\hat{\sigma^{2}}}^{2}=\frac{\sum \hat{\varepsilon}_{t}^{2}}{n-1}
$$

When we replace at equation (10), the values $\hat{\varepsilon}_{t}$ of the Table 5 elevated to square, we estimate the variance of random variable $\varepsilon_{t}$ is $\hat{\sigma}_{t}^{2}=1.1$ million.

With the variance estimation of the random component, the behavior equation of net migration as a function of time was solved completely and it can be used to estimate both, punctual forecasts as of interval, at the short, medium, and long term. 
Table 5. Time, Net Migration, Average Value and Slope in Mexico, 2004-2010

\begin{tabular}{|l|c|c|c|c|}
\hline Year & Time & $\begin{array}{c}\text { Net } \\
\text { Migration } \\
\text { observed }\end{array}$ & $\begin{array}{c}\text { Net migration } \\
\text { Estimated }\end{array}$ & $\begin{array}{c}\text { Residual } \\
\left(\hat{\varepsilon}_{t}\right)\end{array}$ \\
\hline 2004 & 0 & $-507,894$ & $-434,955.9$ & $-72,938.1$ \\
\hline 2005 & 1 & $-267,520$ & $-277,839.8$ & $10,319.8$ \\
\hline 2006 & 2 & $-168,416$ & $-177,477.7$ & $9,061.7$ \\
\hline 2007 & 3 & $-126,607$ & $-113,368.6$ & $-13,238.4$ \\
\hline 2008 & 4 & $-50,094.5$ & -72.417 .3 & $22,322.8$ \\
\hline 2010 & 5 & $-40,405$ & $-46,258.5$ & $-5,853.5$ \\
\hline Mean & 6 & $-40,992$ & $-29,548.9$ & $-11,443.2$ \\
\hline
\end{tabular}

Source: The data of the observed net migration were achieved from Table 1. The estimated net migration was calculated according to the equation (11), and the residuals were calculated based in the equation (9)

\section{Results}

Punctual Forecasts of Net Migration in Mexico, 2011-2020

If we consider the results of the parameters estimation process of the deterministic component and of the variance of the random component, as well as, the validation of the assumptions, finally, the behavior equation of the net migration through time in Mexico is as follows,

$$
S_{t}=-434,955.93 e^{-0.4482 t}+\varepsilon_{t}
$$

Where:

$S_{t}$ is net migration in time $t$,

$t$ denotes time variable, and

The constants $-434,955.93$ and -0.4482 are the mean of net migration in time zero and the constant of the reduction of the population loss respectively, and the $\varepsilon_{t}$ are independent random variables, with Normal distribution, mean $\mu_{\varepsilon}=0$ and constant variance $\hat{\sigma}_{\varepsilon}^{2}$ million.

Giving values to time variable in equation (8) we obtained punctual forecasts of the mean of net migration in Mexico for period 2011-2020 (see Table 6). In the Figure 6, you can observe that the model is adjusted so well to the observed data and when time is increased the mean of net migration approaches zero. According to the model results, we found that in 2012 our country lost 12,057 persons because of international migration, in 2014 they were 4,920, in 2016 we expect that the population loss will be of 2,007 persons, in 2018 it will reduce to 819 and in 2020 there will be a total of 334 habitants. 
Figure 6. Net Migration Observed and Punctual Forecast in Mexico, 2004-2020

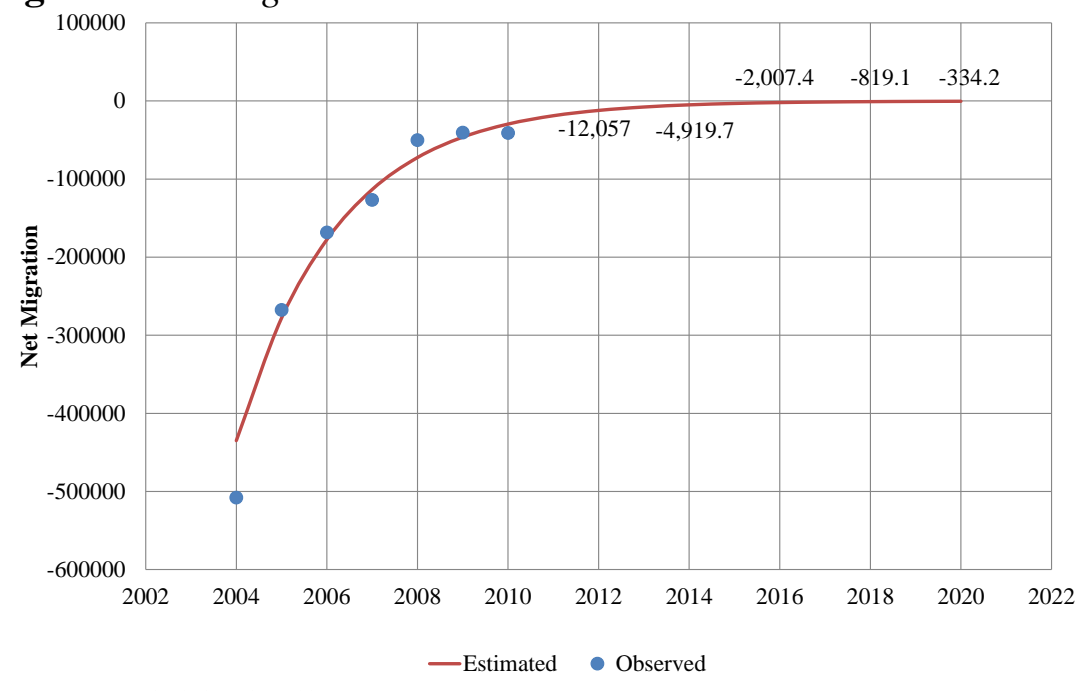

Source: Own calculations based in (8)

In Table 6 we present the absolute reduction of population loss in each year and the percentage reduction. You can observe that calculations confirm what theory says, namely, the annual percentage reduction is 36.12 percent and further is constant.

It is important to point out that the mean of net migration can be predictable because its behavior through time is completely deterministic, however, the behavior of the observations is random, and therefore they cannot be predictable, it is only possible to calculate two numbers between whom for an interest time $t_{0}$, the observation will be between two numbers with a probability of $95 \%$. These two numbers define the confidence interval.

To calculate the interval it is necessary to use the variance estimation of the $\varepsilon_{t}$.

Table 6. Time, Net Migration, Average Value and Slope in Mexico, 2004-2010

\begin{tabular}{|l|c|c|c|}
\hline Year & $\begin{array}{c}\text { Punctual } \\
\text { Forecast }\end{array}$ & $\begin{array}{c}\text { Absolute } \\
\text { reduction }\end{array}$ & $\begin{array}{c}\text { Percentage } \\
\text { reduction }\end{array}$ \\
\hline 2011 & $-18,875.1$ & $-6,818$ & 36.12 \\
\hline 2012 & $-12,057$ & $-4,353.3$ & 36.12 \\
\hline 2013 & $-7,701.1$ & -2.782 .0 & 36.12 \\
\hline 2014 & $-4,919.7$ & $-1,777.1$ & 36.12 \\
\hline 2015 & $-3,142.6$ & $-1,135.2$ & 36.12 \\
\hline 2016 & $-2,007.4$ & -725.1 & 36.12 \\
\hline 2017 & $-1,282.3$ & -463.2 & 36.12 \\
\hline 2018 & -819.1 & -295.9 & 36.12 \\
\hline 2019 & -523.2 & -189 & 36.12 \\
\hline 2020 & -334.2 & & \\
\hline
\end{tabular}

Source: Punctual forecast, own calculations based in equations 11.

Absolute and percentage reduction own calculations based in punctual forecast. 
Confidence Intervals for Net Migration in Mexico, 2011-2020

The methodology to calculate the confidence interval was, first, we calculate the 95 percent confidence interval for the transformation of net migration, and secondly, we apply an inverse transformation in order to get back to the space of net migration and time. So that, the 95 percent confidence interval of net migration is,

$$
-\hat{\gamma} e^{\hat{r}_{0}} \pm t_{\alpha / 2} \hat{\sigma}_{\varepsilon} \sqrt{1+\frac{1}{n}+\frac{\left(t_{0}-\bar{t}\right)^{2}}{\sum\left(t_{0}-\bar{t}\right)^{2}}}
$$

Where:

$-\gamma$ and $r$ are estimations of their respective parameters

$t_{0}$ is time where we want the forecast,

$t_{\alpha / 2}$ is the value of the $t$ Student distribution with $n-2$ degrees of freedom,

which have on the right a probability of $\alpha / 2$,

$\hat{\sigma}_{\varepsilon}$ denotes standard deviation estimation of random variable $\varepsilon_{t}$

$n$ is the data number, and

$\bar{t}$ is average time.

Giving values to equation (12) beginning with $t_{0}=0$ until $t_{0}=16$ were obtained the confidence intervals for the observations of net migration in period 2004-2020. In the Figure 7 we introduce the results. According to the estimations, in México the net migration in 2012 was between -131,349 and 107,235; in 2014 between -147,125 and 137,286; in 2016 it will be between -109,970 and 165,955; in 2018 between $-196,261$ and 194,623; finally in 2020 it will be between $-224,436$ and 223,678. 
Figure 7. Net Migration Observed and Forecast by Interval in Mexico, 2004-2020

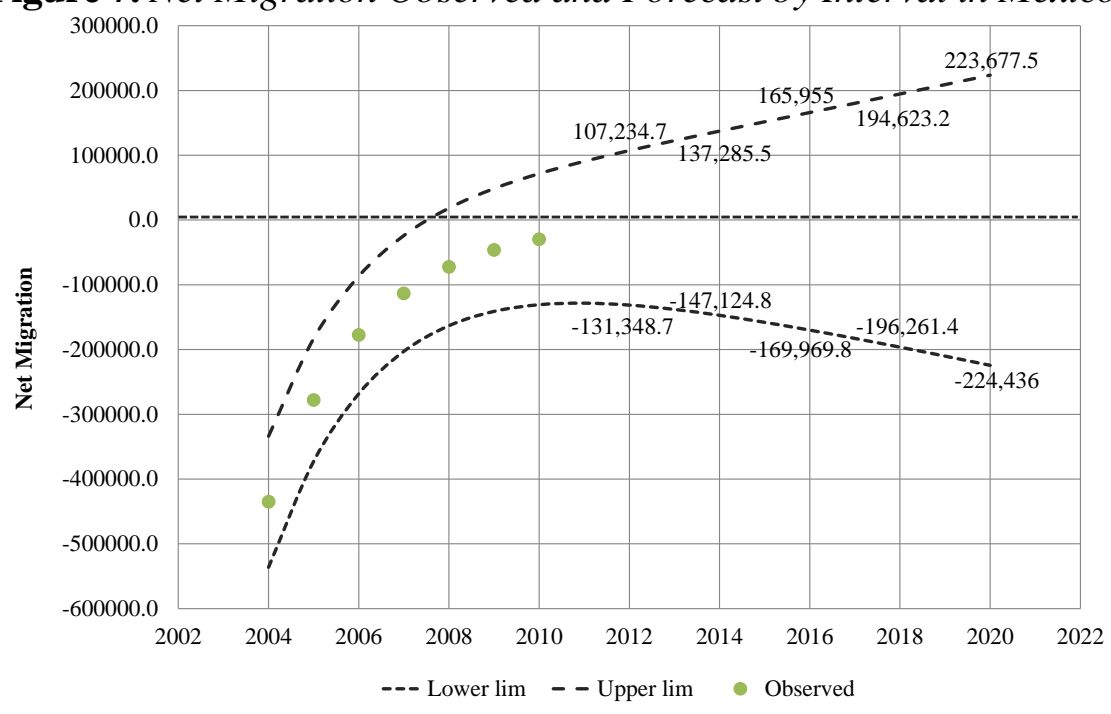

Source: own calculations based at (9)

As you can see, all the observations of the past are between the lines that define the confidence interval, so that, if future is a continuation of past, we expect that the net migration forecast will be within the confidence limits. You can also see, that the confidence band is more wider, if the future time $t$ of the interest is further from the present, what means that uncertainty about what will happen in the future with net migration is each time larger, exhibiting our lack of knowledge about what will happen with the international migration in Mexico.

\section{Discussion}

We found that if we consider the net migration as a random phenomenon then we can explain behavior irregular observed of net migration. But this hypothesis implies we cannot forecast net migration which was one of our big objectives.

However, under above hypothesis net migration has to have a mean and a variance, so that, we assumed the mean had a deterministic behavior given by a mathematical function that depends on time, this fact allowed us to suppose that the mean is bounded.

In order to find the bound of the mean, we used the Stable Bounded Theory, finding that bound is zero.

After that, with data trend and the bound found, using the Stable Bounded Theory again, we were able to find, the equation of net migration and time which describes the behavior of the mean of net migration through time adequately.

With the estimates given by the equation of net migration and time, and the observations, we were able to estimate the variance of net migration. 
Finally, we gave values to time in the equation of net migration and time, and we were able forecast net migration of punctual form. After that, using the variance estimate we estimated the confidence intervals for net migration.

\section{Conclusion}

In Mexico, for the period 2004-2020, the behavior of the net migration through time is governed by a mathematical equation which has two components, one completely predictable and another unpredictable.

The predictable component indicates that the mean of net migration will be predictable in any time and it is determined by three parameters, the bound $K=0$, the initial value in time zero $-\gamma=34$ thousand, and the constant reduction of population loss $r=-0.4482$.

Other results that are very important for Mexico is the reduction of the annual rate of net migration, which is constant and its value is 36.12 percent.

The unpredictable part points out that the value of the observations through time cannot be predictable, and is governed by a probabilistic law which is distributed as a Normal, whose mean is zero, and variance is 1.1 million, and they are independent random variables.

According to the predictable part we expect that in 2016 the mean loss of population in Mexico due to the migration will be of 2,007 persons, in 2018 will be of 819 , and in 2020, 334 persons will leave the country.

According to the unpredictable part, in 2016 with a probability of 95 percent, the value of the net migration will be between a population loss of 64 thousand persons and a gain of 60 thousand, in 2018 there will be a population loss of 63 thousand, and a gain of 61 thousand, and in 2020 there will be between a loss and a gain of 224 thousand persons.

It is necessary to warn that the results of this paper are based on the assumption that the social, economic and political conditions will continue without change. If this assumption is not fulfilled, the forecasts will not be true. An example of this, are the President Barack Obama's initiatives, which at the moment are suspended, but if they were approved, they will have effects that may change the forecasts, a real situation that we should have in mind.

Also it is necessary to warn that the mathematical modeling of reality is based on assumptions, and the theoretical results are true only if the assumptions fulfill, so that, it is necessary to do a great effort to prove that the assumptions are true.

Finally, any exercise to predict the future exposes a lot of error sources: wrong data, false assumptions and hypothesis, wrong models and so on. Therefore, it is necessary to identify all possible error sources, and then utilize the methodologies that minimize those errors. The Stable Bounded Theory is an example of that. 


\section{References}

Alders M, Keilman N, Cruijsen H (2007) Assumptions for long-term stochastic population forecast in 18 European countries. European Journal of Population 23:33-69. Retrieved from http://bit.ly/2nSaUtb. [Accessed 24 March 2017].

Box GE, Jenkins GM (1970) Time series analysis: Forecasting and control. San Francisco: Holden-Day.

Cohen JL (1986) Population forecasts and confidence intervals for Sweden: A comparison of model based and empirical approaches. Demography 23(1). Retrieved from http://bit.ly/2owGCQ1. [Accessed 24 March 2017].

CONAPO (2015) Modelación de fenómenos demográficos: Análisis de las fuentes de información sobre mortalidad, fecundidad y migración internacional en México para determinar las bases empíricas de la Conciliación y Proyecciones de Población. México [Modeling demographic phenomena: Analysis of the sources of information on mortality, fertility and international migration in Mexico to determine the empirical foundations of the Conciliation and Population Projections. Mexico] Unpublished.

Draper J, Smith W (1966) Applied regression analysis. New York: John Wiley \& Sons.

Gonzalez-Rosas J (2010) Teoría estadística y probabilística de los fenómenos estable acotados [Statistical and probabilistic theory of phenomena stable-bounded]. Master thesis. National University Autonomous of Mexico.

Gonzalez-Rosas J (2012) La teoría estable acotada: Fundamentos, conceptos y métodos, para proyectar los fenómenos que no pueden crecer o decrecer indefinidamente [The stable bounded theory: Fundamentals, concepts and methods, to project phenomena that cannot grow or decrease indefinitely]. Saarbrucken, Germany: Spanish Academic editorial.

Hyndman RJ, Booth H (2008) Stochastic population forecasts using functional data models for mortality, fertility and migration. International Journal of Forecasting 24(3). Retrieved from http://bit.ly/2o5eJ0d. [Accessed 22 March 2017].

Lehmann CH (2000) Geometría analítica [Analytic geometry]. México: Editorial Limusa S.A. de C.V.

Leithold L (1973) El cálculo: Con geometría analítica, $2^{\text {nd }}$ ed. [The calculation with analytic geometry]. Mexico: Harla S.A. de C.V.

Lloyd CB (2017) World Population in 2050. Assessing the projections. Discussion, 116-122. Retrieved from http://bit.ly/2owyKxU.

Medhi J (1981) Stochastic processes, $2^{\text {nd }}$ ed. New York: John Wiley \& Sons.

Montgomery DC, Peck EA (1982) Introduction to linear regression analysis. New York: John Wiley \& Sons.

Raymer J, Abel GJ, Rogers A (2012) Does Specification Matter? Experiments with Simple Multiregional Probabilistic Population Projections. NIH Public Access 44(11): 2664-2666. Retrieved from http://bit.ly/2oxyzC3. [Accessed 20 March 2017]. 